\title{
Development of Halal Chinese Fish Sausage Using Different Types of Lipid
}

\author{
Tarit Apisittiwong $^{1^{*}}$, Athip Boonsiriwit ${ }^{2}$, \\ Nut Thephuttee ${ }^{1}$, and Thongchai Thancharoenkul ${ }^{1}$ \\ ${ }^{1}$ Faculty of Food Technology, Rangsit University, Pathum Thani 12000, Thailand \\ ${ }^{2}$ Culinary Arts and Technology Program, Rangsit University, Pathum Thani 12000, Thailand \\ *Corresponding author.E-mail: tarit.a@rsu.ac.th \\ https://doi.org/10.12982/CMUJNS.2019.0001
}

Received: February 2, 2018

Revised: June 2, 2018

Accepted: July 31, 2018

\begin{abstract}
Chinese sausage is in the dried sausage category, has a sweet-savory taste, and can be stored unrefrigerated for several months. It is usually cooked by frying or steaming, and used as an ingredient in rice and vegetable dishes. Its prevailing variety is produced from pork and pork fat, while some varieties are produced from fish but retain pork fat for good texture. Recently, the Asian appetite for sausages significantly expanded its market; unfortunately it is prohibited for Muslims. In this research, a new Chinese sausage formula was developed using fish and vegetable lipids as the main ingredients to make the sausage religiously correct (Halal certified) for Muslim consumers. Pork fat was replaced with $50 \%$ vegetable lipids (vegetable oil, margarine or vegetable shortening) and $50 \%$ bulking agent (3:2 microcrystalline cellulose gel-powdered cellulose or MCG-PC mixture). Sensory characteristics of the finished product were evaluated and the results revealed that a mixture of $14 \%$ vegetable oil and $36 \%$ vegetable shortening represented the most satisfying qualities and overall consumer acceptability. Physicochemical properties of the finished product were investigated and showed that moisture content, water activity $\left(a_{w}\right)$ and firmness were $7.75 \%, 0.48$, and $145.78 \mathrm{~g}$, respectively. Microbiological qualities including total bacterial count, Salmonella spp., Staphylococcus aureus, Escherichia coli, as well as yeast and mold count were tested and negative results were obtained. Overall results indicated that vegetable lipids and MCG-PC mixture can be used as a pork fat substitute in Chinese fish sausage for Muslim consumers.
\end{abstract}

Keywords: Chinese sausage, Fish sausage, Halal food, Fat replacer, Vegetable lipid, Sensory evaluation 


\section{INTRODUCTION}

The word halal refers to purity or a symbol of a commitment to prepare food in accordance with Islamic law (Riaz and Chaudry, 2004). According to the Koran, many special conditions on diets are imposed, especially the abstinence from swine and alcohol products. At present, the global demand for halal food is expected to increase significantly due to the growth in the Muslim population and their strict adherence to Islamic dietary laws.

Sausage is a product that can be prepared from various types of meat and is already a well-accepted product in the commercial market. Fresh comminuted meat and ingredients used as raw materials in the formulation can be modified to yield desirable organoleptic and keeping qualities of the product (Prabpree and Pongsawatmanit, 2011). Chinese or Cantonesestyle sausage, also called Kunchiang in Thailand, is the traditional way to preserve meat. Since it is a good source of protein that can be easily cooked and used as an ingredient in many dishes, it is kept in every household. It is normally made of pork or chicken mixed with pork fat (Heinz and Hautzinger, 2007). Thus, Chinese sausage by nature was haram or forbidden due to its composition.

Fish is a top-of-the-line nutrient-dense food. It is low in fat and rich in many healthy substances (Sini et al., 2008). Production of sausage from different species of marine fish and surimi have been reported in many previous studies, however production from freshwater fish is still lagging behind. Various types of freshwater fish in Asia have been used as a raw material to produce sausages (emulsion, fermented or dried sausages) such as catfish, golden carp, rohu, silver carp, small scale mud carp, and Tigris scraper (Raksakulthai et al., 2004; Panpipat and Yongsawatdigul, 2008; Sini et al., 2008; Xu et al., 2010; Prabpree and Pongsawatmanit, 2011; Ozpolat and Guran, 2017; Ozpolat and Patir, 2017). Julian's golden carp (Probarbus jullieni) is commonly found in river basins of many countries in Southeast Asia and are aquacultured mainly in Thailand and Laos. Due to increase in demand of freshwater fish consumption, aquaculture production of Julian's golden carp is growing annually at a rate of $3.86 \%$ globally according to the FAO statistics (Ali et al., 2018).

Even though fish sausage or even Chinese fish sausage can easily be found in markets, most of them contained pork fat to ensure the crisp texture of the sausage. Many studies have been conducted to partially reduce or completely eliminate pork fat from Chinese sausage using various categories and types of fat replacers (Tan et al., 2007; Lin and Huang, 2008; Feng et al., 2013). However those studies were aimed to produce a healthier sausage with low or no pork fat rather than to produce a halal sausage that excludes both pork and pork fat. As Chinese sausage is conventionally used in many Chinese dishes, many Muslim consumers need to refrain from most Chinese dishes, making their dietary choices narrower than other consumer groups. Life would be more difficult for Chinese Muslim consumers, who have grown accustomed to the gustatory taste of Chinese food but need to refrain from consumption.

Thus, the objective of this research was to develop a Chinese fish sausage that satisfies the criteria for halal certification using vegetable lipids of various types and ratios as a pork fat replacer with overall qualities as similar to the original Chinese sausage as possible. 


\section{MATERIALS AND METHODS}

\section{Materials}

Fresh Julian's golden carp meat was bought from Siam Makro, Pathum Thani, Thailand. The meat was trimmed and portions of approximately $1 \mathrm{~kg}$ were packed in PE bags, frozen and stored at $-18^{\circ} \mathrm{C}$ for $24 \mathrm{~h}$. Ingredients used as pork fat replacement included: vegetable shortening (composed of soybean oil, fully hydrogenated palm oil, palm oil, diglycerides, monoglycerides, TBHQ, and citric acid) (Crisco, The J.M. Smucker Company, Orrville, Orlando, USA); margarine (composed of Palm oil, iodized salt, emulsifier, acidity regulator, sequestrant, natural color and artificial flavor) (Best Foods, Unilever Thai Trading, Bangkok, Thailand); palm oil (Oleen, O L Palm, Samutsakorn, Thailand).

Microcrystalline cellulose (MCC) (VIVAPUR, J. Rettenmaier and Söhne, Rosenburg, Germany) and powdered cellulose (PC) (VITACEL, J. Rettenmaier and Söhne, Rosenburg, Germany) were used as bulking agents. Bulking agents were prepared using a chopper (MAINCA CM-14 bowl cutter, Equipamientos Carnicos S.L., Barcelona, Spain). The microcrystalline cellulose gel (MCG) was prepared by mixing 1 part of MCC with 4 parts of water and 4 parts of ice until the gel was formed. The temperature of the MCG at the end of mixing process was less than $18^{\circ} \mathrm{C}$ and it was kept at $-18^{\circ} \mathrm{C}$ for $15 \mathrm{~min}$. PC was prepared by mixing with 5 parts of water. Six parts of MCG and 4 parts of PC were mixed and used as a bulking agent mixture. Others additives and seasonings used were soy protein isolate (SPI), sodium triphosphate (STP), sodium chloride, sodium nitrite (Chemipan Corporation, Bangkok, Thailand) and sugar (Mitr Phol Sugar Corporation, Bangkok, Thailand).

\section{Preparation of Chinese fish sausage}

Fish meat packages were thawed prior to use. Four different sausages were prepared according to Table 1. Control formula with pork fat was not included since some consumers who participated in product acceptance test were Muslim.

Table 1. Formulation of Chinese fish sausage.

\begin{tabular}{lcccccccc}
\hline \multirow{2}{*}{ Samples } & \multicolumn{8}{c}{ Weight ratio (kg) } \\
\cline { 2 - 10 } & $\begin{array}{c}\text { Fish } \\
\text { meat }\end{array}$ & Shortening & Margarine & $\begin{array}{c}\text { Palm } \\
\text { oil }\end{array}$ & MCG & PC & SPI & STP \\
\hline FS/S & 3.00 & 1.75 & - & - & 1.05 & 0.70 & 0.025 & 0.025 \\
FS/M & 3.00 & - & 1.75 & - & 1.05 & 0.70 & 0.025 & 0.025 \\
FS/O & 3.00 & - & - & 1.75 & 1.05 & 0.70 & 0.025 & 0.025 \\
FS/S+O & 3.00 & 1.25 & - & 0.50 & 1.05 & 0.70 & 0.025 & 0.025 \\
\hline
\end{tabular}


Raw meat and STP were chopped in a chilled meat chopper (Mainca CM-14, Equipamientos Carnicos S.L., Barcelona, Spain) for $1 \mathrm{~min}$. Fat replacers were added (depending on the formulation) to chopped meat and mixed until a homogenous mass was formed. Bulking agents (mixture of MCG and PC), SPI and sugar were added and mixed again for 1 min. Final batter temperature was below $12^{\circ} \mathrm{C}$ in all formulas. The batter was stuffed into $23 \mathrm{~mm}$ edible collagen casings (F230 clear type, halal certified, Nippi Collagen Industries Ltd., Shizuoka, Japan) using 12 L tabletop sausage filler (Friedr Dick GmbH \& Co. KG, Deizisau, Germany) and hand-linked (25 cm in length). Sausages were dried in a hot air dryer (FnB Machinery \& Solutions Co. Ltd., Bangkok, Thailand) at $60^{\circ} \mathrm{C}$ for 6 days. The sausages were then cooled at room temperature, packed in a PE bag without vacuum, and placed in a dried chamber until analysis.

To ensure that the product meet the requirement for halal, fish meat and other ingredients used were kept separately from non-halal items in a single-use disposable container. Processing equipment and production procedures were properly controlled according to Thai Agricultural Commodity and Food Standard (TACFS) 8400-2007 (Thailand National Bureau of Agricultural Commodity and Food Standards, 2007).

\section{Sensory analysis}

Chinese fish sausages were assessed by 10 food experts who were familiar with meat and fishery products, particularly Chinese sausage. The expert panel tested and selected the most satisfying sausage formula by ranking method (Stone et al., 2012) based on appearance (including color), odor and texture.

\section{Physicochemical properties}

Physicochemical properties of the Chinese fish sausages were investigated including moisture content, water activity $\left(\mathrm{a}_{\mathrm{w}}\right)$, firmness, and toughness. Moisture content was determined according to AOAC method (AOAC, 2012). Water activity was measured by $\mathrm{a}_{\mathrm{w}}$ meter (AquaLab Series 3TE, Decagon Devices Inc., Pullman, Washington, USA). Puncture tests were performed at room temperature by a texture analyzer (TA.XT plus, Stable Micro Systems, Surrey, UK) with a $6 \mathrm{~mm}$ diameter stainless steel flat-ended cylindrical probe (P/6) attached to a $50 \mathrm{~kg}$ load cell. Force-time curves were obtained and analyzed. Firmness and toughness of each sample were derived from these curves. Firmness is defined as a maximum force $(\mathrm{N})$ exerted at the point in which a sample is being penetrated, while toughness is defined as work of penetration (N.s) required for a sample to be penetrated (the area under force-time curve).

\section{Microbiological qualities}

The Chinese fish sausage formula selected by group of experts during a sensory analysis was further analyzed for microbiological qualities as required by the Thai Community Product Standard (TCPS) 104-2555 (Thai Industrial Standards Institute, 2012). The sample was analyzed for total bacterial count, yeast and mold count, and pathogenic bacteria (Salmonella spp., Staphylococcus aureus, and Escherichia coli) according to AOAC method (AOAC, 2012). 


\section{Consumer acceptance test}

The selected Chinese fish sausage formula was also evaluated by 100 randomly selected consumers of different genders, age ranges, education levels, occupations and incomes. Sensory characteristics were evaluated including appearance, color, odor, taste, texture and overall acceptability using 7-point hedonic scale (Stone et al., 2012).

\section{Statistical analysis}

Analysis of variance (one-way ANOVA) and Tukey's multiple range test were conducted to investigate the statistical significance $(P<0.05)$ of the effect of the sausage formulation with different pork fat replacers on the physicochemical properties of Chinese fish sausages.

\section{RESULTS}

\section{Sensory evaluation}

Halal Chinese fish sausages formulated with different types of vegetable lipid were manufactured. The sausage samples also included a microcrystalline cellulose gel-powdered cellulose (MCG-PC) mixture as a bulking agent (total lipid content was reduced from a typical Chinese sausage formula by $50 \%$ ). Each sample (Table 2) was then evaluated by a 10 expert panel (Figure 1). It was revealed that there were some defects in samples FS/S, FS/M and $\mathrm{FS} / \mathrm{O}$ that the expert panel felt were unacceptable.

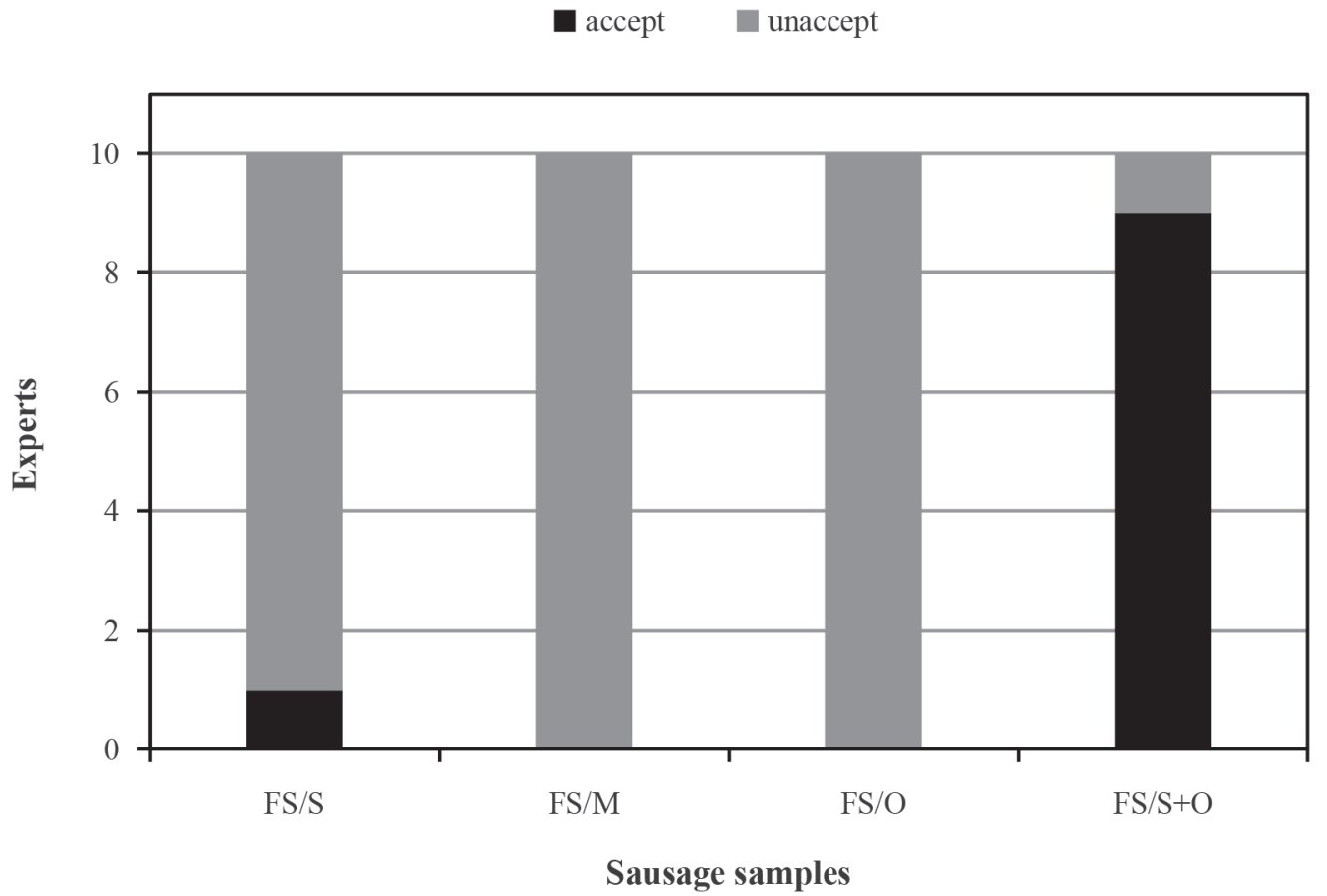

Figure 1. Number of food experts acceptance on each sausage sample. 
Only 1 expert accepted sample FS/S. Its appearance was rejected by others expert due to dispersed white stains on the sausage surface (outer surface of collagen casing), although odor and texture were acceptable. None of experts accepted sample FS/M. Its appearance and texture were satisfactory but exhibited a poor odor. All experts rejected sample FS/O, complaining that texture was undesirable even though the appearance and odor were acceptable. Nine out of 10 experts preferred sample $\mathrm{FS} / \mathrm{S}+\mathrm{O}$ in which pork fat was replaced by mixture of palm oil (14\%), shortening (36\%) and MCG-PC (50\%). One expert rejected FS/S+O due to its texture however other experts said the texture was acceptable. Internal appearance of sample $\mathrm{FS} / \mathrm{S}+\mathrm{O}$ (Figure 2B) revealed a finer structure than the control sample (Figure 2A) in which pork fat was clearly visible.

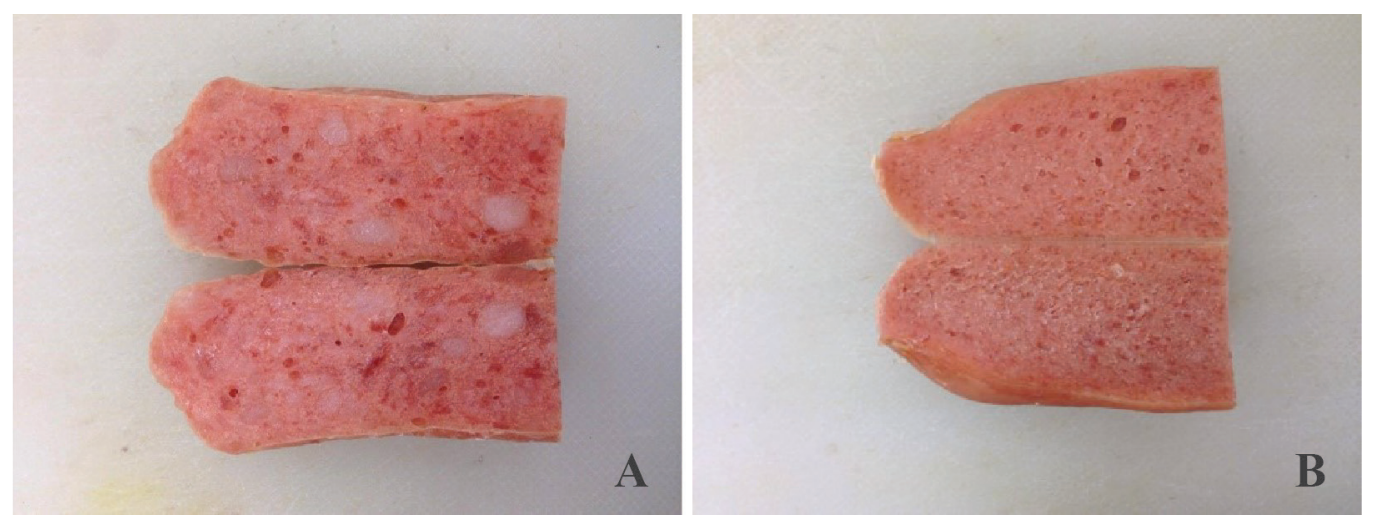

Figure 2. Sausage internal appearance: A) with pork fat, B) without pork fat (sample FS/ $\mathrm{S}+\mathrm{O})$.

\section{Physicochemical properties}

Physicochemical properties of each sample are shown in Table 2. Moisture content of all samples was insignificantly different $(P>0.05)$ ranging from about $4 \%$ to $9 \%$. Water activity of each sample was low, ranging from 0.48 to 0.54 . FS/O had the highest $\mathrm{a}_{\mathrm{w}}$ while FS/ $\mathrm{S}+\mathrm{O}$ had the lowest. Sample FS/O presented the highest firmness and toughness values. No differences in firmness and toughness between $\mathrm{FS} / \mathrm{S}$ and $\mathrm{FS} / \mathrm{S}+\mathrm{O}$ were found. Firmness and toughness values of FS/M were significantly higher than FS/S and FS/S+O. 
Table 2. Physicochemical properties of Halal Chinese fish sausage formulated with different types of vegetable lipid.

\begin{tabular}{lcccc}
\hline Samples & Moisture content (\%) & Water activity & Firmness $(\mathbf{N})$ & Toughness $(\mathbf{N . s})$ \\
\hline FS/S & $6.98 \pm 1.89^{\mathrm{a}}$ & $0.507 \pm 0.006^{\mathrm{b}}$ & $14.222 \pm 0.845^{\mathrm{a}}$ & $88.753 \pm 2.924^{\mathrm{a}}$ \\
$\mathrm{FS} / \mathrm{M}$ & $5.14 \pm 0.55^{\mathrm{a}}$ & $0.507 \pm 0.005^{\mathrm{b}}$ & $18.273 \pm 0.270^{\mathrm{b}}$ & $101.361 \pm 1.340^{\mathrm{b}}$ \\
FS/O & $4.78 \pm 0.83^{\mathrm{a}}$ & $0.535 \pm 0.008^{\mathrm{c}}$ & $20.472 \pm 1.006^{\mathrm{c}}$ & $120.859 \pm 3.137^{\mathrm{c}}$ \\
FS/S $+O$ & $7.75 \pm 1.37^{\mathrm{a}}$ & $0.480 \pm 0.002^{\mathrm{a}}$ & $14.297 \pm 0.590^{\mathrm{a}}$ & $89.464 \pm 5.738^{\mathrm{a}}$ \\
\hline
\end{tabular}

Note: Different letters in the same column indicate significant differences $(P<0.05)$.

\section{Microbiological qualities}

To assure consumer safety, sausage sample FS/S+O which was chosen over other samples following sensory evaluated by expert panel was tested for microbiological standard according to TCPS 104-2555 standard (Thai Industrial Standards Institute, 2012). The results showed that all microbial qualities of the sausage complied with the specified standard (data not shown). Total bacterial count was less than $6 \mathrm{CFU} / \mathrm{g}$. Yeast and mold, and Staphylococcus aureus were less than $100 \mathrm{CFU} / \mathrm{g}$. Escherichia coli was less than $3 \mathrm{MPN} / \mathrm{g}$. No Salmonella spp. was found in $25 \mathrm{~g}$ of sausage. The results confirmed that reduction of $\mathrm{a}_{\mathrm{w}}$ was able to control both spoilage and pathogenic microorganisms.

\section{Consumer acceptance}

Sample FS/S+O was further evaluated by 100 consumers to assess the product acceptance. Demographic data revealed that the majority of the consumer panel was female between 20-30 years of age (Figure 3A and 3B), mainly consisting of college students and people in early working age. They represented young consumers in Thailand's current urban-suburban societies who are acquainted with food influenced by Chinese cuisine. This observation was supported by the evidence that Chinese fish sausage was recognized by $78 \%$ of the consumer panel and 80\% revealed that they liked this product (Figure 4A and 4B). Since this product is not limited to Muslim consumer, religion was excluded from the demographic data and indeed some consumers who assessed this product are Muslim.

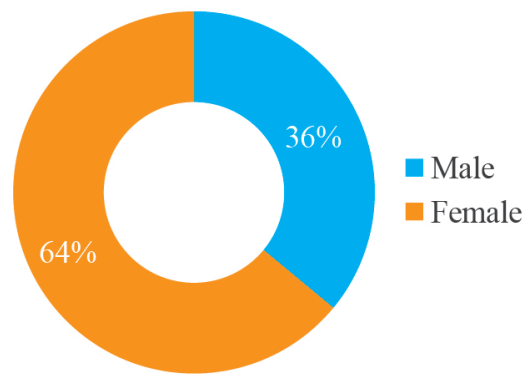

A

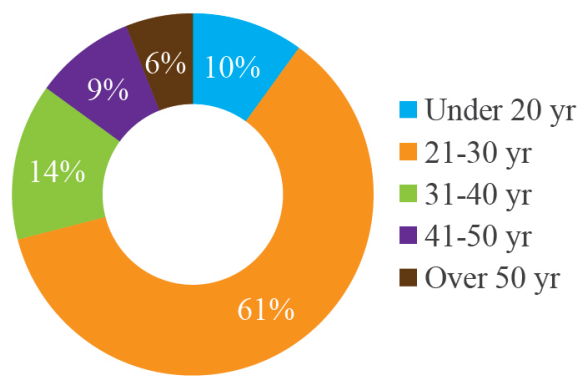

B

Figure 3. Demographic data of consumer panel: A) gender, B) age. 
However, more than half of consumer panel (54\%) disbelieved that Chinese fish sausage being sold in the market currently conformed to Halal product standards for both raw materials used and how they were manufactured (Figure 4C). They did not state their reasons behind their distrust in the product, but one of the reasons could be the common use of pork fat as a lipid portion in the product. This was perhaps the reason why $78 \%$ of consumer panel decided to buy our product if it is actually being offered to the market in the future (Figure 4D).

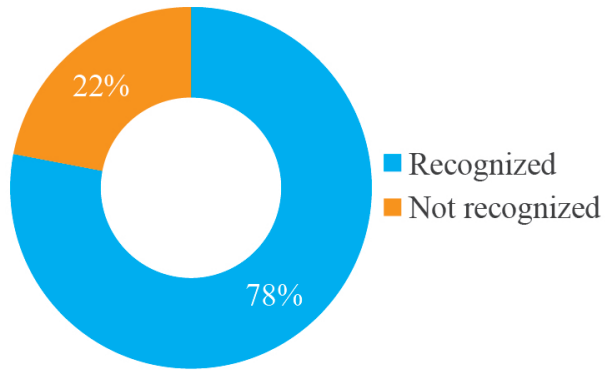

A

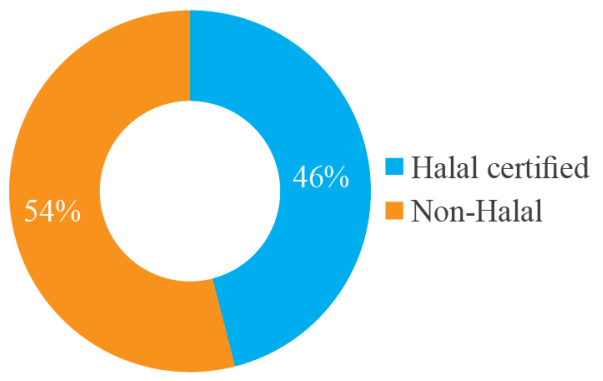

C

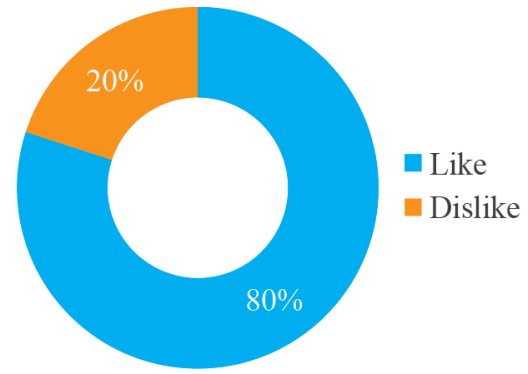

B

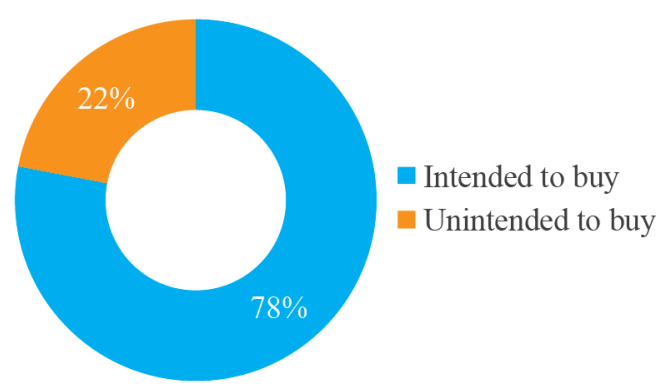

D

Figure 4. Consumer behaviors towards Chinese fish sausage: A) product recognition, B) overall product likeliness, C) consumer trust in halal certification, D) intention of purchasing Halal Chinese fish sausage. 
Sample FS/S+O was then offered to the consumer panel described earlier, together with a questionnaire in which each sensory characteristics of the product was asked to be rated by likeliness score of 1 to 7 (7-points hedonic scale). These included appearance, color, odor, taste, texture, and overall liking. The results revealed that except for the product's texture, other sensory characteristics received an average score of more than 6 (Figure 5), which means that consumers moderately like or very much like these product characteristics. Although texture score was low, its average score was well over 5. This pointed out that consumers accepted and slightly liked the texture of the product. Thus, it can be implied that Chinese fish sausage could be produced according to Halal food standards by using a vegetable lipid (mixture of palm oil and shortening) instead of pork fat. Also MCG-PC mixture could be used as a bulking agent to reduce the fat content in the product by $50 \%$.

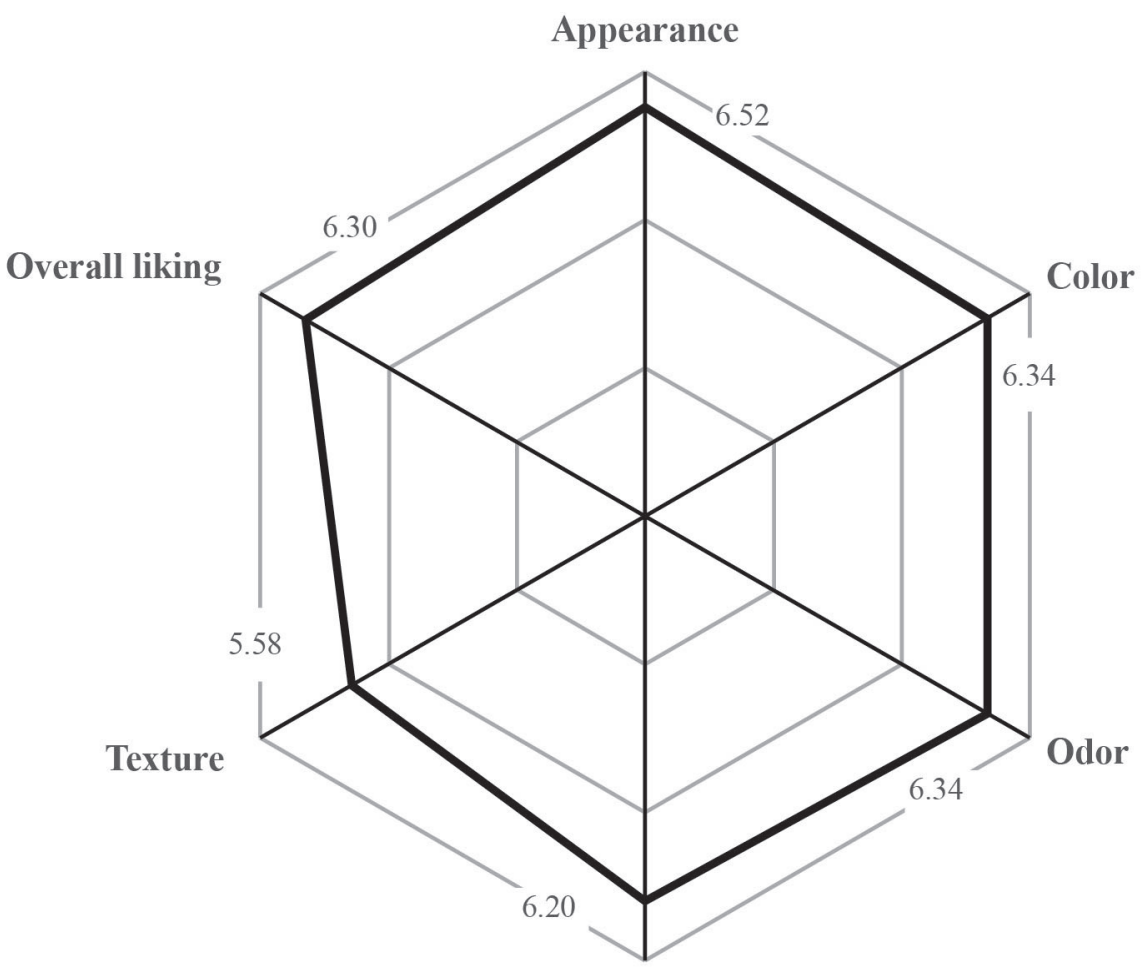

Taste

Figure 5. Likeliness score of various sensory characteristics of Halal Chinese fish sausage. 


\section{DISCUSSION}

The appearance of sample FS/S was rejected due to white stains on the surface. These stains originated from lipid exudate during drying of the sausage. As this defect was undetectable on 3 other samples $(\mathrm{FS} / \mathrm{M}, \mathrm{FS} / \mathrm{O}$ and FS/S+O), the sausage drying step itself was unlikely to be the root cause of the defect. But the defect was seemingly accelerated by the drying step which caused shrinkage of sausage and drove a liquefied lipid to the outer surface of the sausage. Normally lipid globules in a sausage are stabilized by meat proteins (interfacial protein film) or entrapped in a protein matrix (network of protein) (Barbut, 1999). Meat emulsion is said to have good stability when lipids are efficiently kept within a sausage structure by either type of stabilization. Hence sample FS/S probably presented poor emulsion stability leading to a lipid exudate. This may be explained by the difference in physical properties of shortening (hydrogenated vegetable oil) from pork fat even though both are a solid form of lipid at room temperature and did not affect the sample texture. Delgado-Pando et al. (2011) reported that when pork fat was replaced by pre-emulsified oil, protein matrix formation in the sausage was interfered. The matrix structure that was formed was compact and had fewer pores in comparison to the regular structure. They proposed that these changes originated from the better distribution and smaller size of oil globules as opposed to pork fat globules, and oil globules were embedded in the matrix structure. Since FS/S exhibited normal texture, it can be inferred that size and distribution of lipid globules in FS/S had no interference on protein matrix formation.

Sample FS/M had an unsatisfactory odor that can be traced back to the specific odor of margarine that affected the inherent flavor of the sausage, since margarine may contain small amounts of skim milk or skim milk powder to imitate butter flavor (Belitz et al., 2009). FS/M also presented normal texture as FS/S, thus it can be implied that the protein matrix was unchanged as well. Appearance of FS/M showed no sign of lipid exudate, thus stability of meat emulsion in FS/M could be good enough to hold the lipid phase effectively.

The undesirable texture of FS/O might be explained by similar reasons as mentioned above in the report of Delgado-Pando et al. (2011). Although the size of palm oil globules was not comparable to emulsified oil globules, it was smaller than pork fat globules in regular sausages.

Although the lipid content of sample FS/S+O was lowered by as much as $50 \%$, all of its sensory characteristics remained acceptable including appearance, odor and texture. As lipids play a major role in formation of sausage structure, sausage texture could be the most likely sensory characteristic to be affected by lipid reduction. Alvarez and Barbut (2013) suggested that lipid reduction lead to increased denser and tighter protein matrix especially after the sausage was cooked, since there were not enough lipid globules to support and maintain the matrix structure. To mitigate this undesirable attribute, they reported that incorporating a 
bulking agent acted as a gap filler occupying the space left in the matrix by the lipids. They also indicated that unevenly distributed bulking agent triggered the discontinuation of protein matrix and negatively affected sausage texture. In this research, sausage sample FS/S $+\mathrm{O}$ still retained its normal texture even after the sausage was dried. From a sensory point of view, it can be implied that addition of MCG-PC can compensate for the reduction of lipids in Chinese fish sausage. The results also suggested that MCG-PC was evenly distributed, did not interfere with protein matrix formation and occupied the space in the protein matrix. MCC itself can form a colloid with rheology similar to that of fat, setting up an insoluble network that immobilized water and imparted a creamy mouthfeel (Kirk et al., 2008). In addition, PC can retain water or oil, up to 10 or 8.5 times of its weight respectively, and can prevent the separation of fat and water in meat product (Cho et al., 1999). Although palm oil was used in $\mathrm{FS} / \mathrm{S}+\mathrm{O}$ to help increase meat emulsion stability and eliminated lipid exudate that negatively impacted FS/S appearance, the amount of oil was not high enough to cause a serious interference on protein matrix and significantly influenced texture of FS/S+O.

Water activity of each sample was below 0.86 , the value specified in Thai Community Product Standard for dried fish sausage or Kunchiang Pla (TCPS 104-2555) (Thai Industrial Standards Institute, 2012). It is important to note that lowering $\mathrm{a}_{\mathrm{w}}$ is necessary to control and prevent spoilage of Chinese sausage and to achieve its desirable shelf-life. Generally, this is accomplished by the combination effect of high sugar content and dehydration (Heinz and Hautzinger, 2007). The ability of MCG and PC to retain or immobilize water may help lowering of $\mathrm{a}_{\mathrm{w}}$ as well. The significant difference in $\mathrm{a}_{\mathrm{w}}$ among the samples may be related to specific internal structures of each sample depending on the type of lipid used, as all samples contained equal amounts of sugar, $\mathrm{MCG}$ and $\mathrm{PC}$, and were subjected to similar drying conditions. Since Chinese fish sausage is categorized as a dried sausage, total expressible fluid (a quality parameter which can be used to describe water holding capacity and juiciness of the product) became less significant and was not included in the experiment.

The highest firmness and toughness values of sample FS/O were consistent with the fact that expert panels rejected FS/O due to its undesirable texture. Insignificant differences in firmness and toughness between $\mathrm{FS} / \mathrm{S}$ and $\mathrm{FS} / \mathrm{S}+\mathrm{O}$ confirmed the expert panel judgment that the texture of these 2 samples was satisfactory. Thus, it can be implied that the limited used of palm oil in $\mathrm{FS} / \mathrm{S}+\mathrm{O}$ did not affect the formation of protein matrix leading to textural changes. Although firmness and toughness values of FS/M were significantly higher than FS/S and FS/ $\mathrm{S}+\mathrm{O}$, it wasn't rejected by the expert panels as they reported that texture of sample FS/M was normal. This result may be due to the fact that either the difference in firmness and toughness values were less than the threshold level of detection of the expert panel or the increase in these values of FS/M was within the acceptable limits established by each expert panelist. 


\section{CONCLUSION}

In conclusion, since food is an important part of daily life, food laws carry a special significance. Muslims are expected to eat Halal food for ethics purposes and maintain good health. The study aimed capitalized on the growth of the Muslim population and to meet the demand of Halal consumption especially in China and Thailand and to launch a Halal fish sausage product with good eating qualities. Thus, Chinese fish sausage formulated without pork fat but using vegetable lipid and microcrystalline cellulose gel-powdered cellulose (MCG-PC) mixture instead is the best choice, resulting in appearance, odor, texture, and overall acceptance of the product which was desired by both food experts and Muslim consumers. Furthermore to better understand keeping quality of this novel product, study could be subsequently conducted to determine the product stability during storage including parameters such as oxidative stability of vegetable lipid.

\section{ACKNOWLEDGEMENT}

This research was financially supported by Rangsit University.

\section{REFERENCES}

Ali, A.M.M., Kishimura, H., and Benjakul, S. 2018. Extraction efficiency and characteristics of acid and pepsin soluble collagens from skin of golden carp (Probarbus Jullieni) as affected by ultrasonication. Process Biochemistry. 66: 237-244. https://doi. org/10.1016/j.procbio.2018.01.003

Alvarez, D., and Barbut, S. 2013. Effect of inulin, $\beta$-glucan and their mixtures on emulsion stability, color and textural parameters of cooked meat batters. Meat Science. 94: 320327. https://doi.org/10.1016/j.meatsci.2013.02.011

AOAC. 2012. Official methods of analysis of AOAC international. $19^{\text {th }}$ ed. The Association of Official Analytical Chemists, Virginia.

Barbut, S. 1999. Advances in determining meat emulsion stability. In: Xiong, Y.L., Ho, C., and Shahidi, F. (eds) Quality attributes of muscle foods. Kluwer Academic / Plenum Publishers, New York. p.353-364.

Belitz, H.D., Grosch, W., and Schieberle, P. 2009. Food chemistry. $4^{\text {th }}$ ed. Springer-Verlag, Berlin.

Cho, S.S., Prosky, L., and Dreher, M. 1999. Complex carbohydrates in foods. Marcel-Dekker, New York.

Delgado-Pando, G., Cofrades, S., Ruiz-Capillas, C., and Solas, M.T. 2011. Low-fat frankfurters formulated with a healthier lipid combination as functional ingredient: microstructure, lipid oxidation, nitrite content, microbiological changes and biogenic amine formation. Meat Science. 89: 65-71. https://doi.org/10.1016/j.meatsci.2011.03.022

Feng, T., Ye, R., Zhuang, H., Rong, Z., Fang, Z., Wang, Y., Gu, Z., and Jin, Z. 2013. Physicochemical properties and sensory evaluation of Mesona Blumes gum/rice starch mixed gels as fat-substitutes in Chinese Cantonese-style sausage. Food Research International. 50: 85-93. https://doi.org/10.1016/j.foodres.2012.10.005 
Kirk, R.E., Othmer, D.F., and Seidel, A. 2008. Kirk-Othmer food and feed technology. John Wiley \& Sons, Hoboken, New Jersey.

Heinz, G., and Hautzinger, P. 2007. Meat processing technology for small to medium scale producers. Food and Agricultural Organization of the United Nations, Bangkok.

Lin, K.W., and Huang, C.Y. 2008. Physicochemical and textural properties of ultrasounddegraded konjac flour and their influences on the quality of low-fat Chinese-style sausage. Meat Science. 79: 615-622. https://doi.org/10.1016/j.meatsci.2007.10.026

Ozpolat, E., and Guran, H.S. 2017. Combined effect of sodium polyphosphate and smoking on quality parameters of fish (Capoeta umbla) sausage. Iranian Journal of Fisheries Sciences. 16: 86-95.

Ozpolat, E., and Patir, B. 2017. Combined effect of different casing and liquid smoked concentration on the shelf-life of sausages produced from fish (Capoeta umbla). Indian Journal of Animal Research. 51: 956-961. https://doi.org/10.18805/ijar.v0iof.6821

Panpipat, W., and Yongsawatdigul, J. 2008. Stability of potassium iodide and omega-3 fatty acids in fortified freshwater fish emulsion sausage. LWT - Food Science and Technology. 41: 483-492. https://doi.org/10.1016/ j.lwt.2007.03.013

Prabpree, R., and Pongsawatmanit, R. 2011. Effect of tapioca starch concentration on quality and freeze-thaw stability of fish sausage. Kasetsart Journal (Natural Science). 45: 314324.

Raksakulthai, N., Chantikul, S., and Chaiyawat, M. 2004. Production and storage of Chinese style fish sausage from hybrid clarias catfish. Kasetsart Journal (Natural Science). 38: 102-110.

Riaz, M.N., and Chaudry, M.M. 2004. Halal food production. CRC Press, Boca Raton, Florida.

Sini, T.K., Santhosh, S., Joseph, A.C., and Ravisankar, C.N. 2008. Changes in the characteristics of rohu fish (Labeo rohita) sausage during storage at different temperatures. Journal of Food Processing and Preservation. 32: 429-442. https://doi.org/10.1111/j.17454549.2008.00188.x

Stone, H., Bleibaum, R.N., and Thomas, H.A. 2012. Sensory evaluation practices. $4^{\text {th }}$ ed. Academic Press, New York.

Tan, F.J., Liao, F.Y., Jhan, Y.J., and Liu, D.C. 2007. Effect of replacing pork backfat with yams (Dioscorea alata) on quality characteristics of Chinese sausage. Journal of Food Engineering. 79: 858-863. https://doi.org/10.1016/j.jfoodeng.2006.03.006

Thai Industrial Standards Institute. 2012. Thai community product standard for dried fish sausages or kunchiang pla (TCPS 104-2555). Ministry of Industry, Bangkok.

Thailand National Bureau of Agricultural Commodity and Food Standards. 2007. Thai agricultural commodity and food standard for halal food (TACFS 8400-2007). Ministry of Agriculture and Cooperatives, Bangkok.

Xu, Y., Xia, W., Yang, F., Kim, J.M., and Nie, X. 2010. Effect of fermentation temperature on the microbial and physicochemical properties of silver carp sausages inoculated with Pediococcus pentosaceus. Food Chemistry. 118: 512-518. https://doi.org/10.1016/j. foodchem.2009.05.008 